\title{
CONSTRUÇÕES RESULTATIVAS INFINITIVAS EM PORTUGUÊS BRASILEIRO
}

- RESUMO: O objetivo deste trabalho é retomar a discussão sobre construções resultativas em português brasileiro, presentes especialmente nos trabalhos de Lobato (2004) e Barbosa (2008). Argumentamos que, embora do ponto de vista sintático essas construções sejam diferentes em português e inglês (ver MARCELINO, 2007; BARBOSA, 2008), do ponto de vista semântico, é possível que se encontrem similaridades entre elas. Nossa proposta parte da análise sobre o fenômeno apresentada em Parsons (1990): ao traçar um paralelo entre sentenças como "John hammered the metal flat" - chamadas pelo autor de "resultative tags" - e "João martelou a lata até achatar", concluímos que esta sentença em português tem as mesmas propriedades semânticas e a mesma forma lógica das resultative tags em inglês. Isso nos leva a assumir que o português brasileiro possui, sim, construções resultativas (ao contrário do que afirma Barbosa), mas que essas construções não são aquelas propostas por Lobato (2004), tais como "Maria cortou o cabelo curto". Nesse caso, entendemos que está correta a observação de Barbosa (2008) de que essas construções se relacionam ao estado resultante e não a construções resultativas como ocorre no inglês.

- PALAVRAS-CHAVE: Estado. Modificação. Preposição "até". Resultativas. Semântica de eventos.

\section{Introdução}

Este trabalho tem como objetivo verificar se as chamadas resultative tags ou simplesmente resultativas do inglês possuem alguma construção sintática ou semanticamente semelhante em português brasileiro (PB). Um exemplo clássico desse tipo de resultativa é a sentença em (1), em que o adjetivo "flat" tem o papel de delimitar a atividade denotada pelo evento "John hammering the metal".

(1) John hammered the metal flat. John martelou o metal chato/achatado 'John martelou o metal até achatar'.

* UTFPR - Universidade Tecnológica Federal do Paraná. Departamento de Comunicação e Expressão. Curitiba PR - Brasil. 80.230-901 - bertucci@utfpr.edu.br 
O nome resultativa vem exatamente do fato de a sentença apresentar um resultado ("achatado") que a ação verbal ("martelar") provoca no objeto ("o metal"); esse resultado é dado em inglês por um adjetivo, no caso "flat".

A construção resultativa é diferente de outras que também apresentam um estado resultante, como em (2), em que o estado final do evento de fechar a porta em (2a) é o fato de a porta estar fechada, e o estado final do evento de construir a ponte em (2b) é o fato de a ponte estar construída.

(2) a. João fechou a porta. $\rightarrow$ A porta está fechada.

b. O engenheiro construiu a ponte. $\rightarrow$ A ponte está construída.

Na literatura sobre aspecto lexical, "fechar a porta" é entendido como um predicado que denota uma mudança de estado instantânea, chamado de achievement, enquanto "construir a ponte" é um predicado que denota um evento composto, com um processo e uma culminação, chamado de accomplishment (ver VENDLER, 1967; WACHOWICZ; FOLTRAN, 2006; WACHOWICZ, 2008, entre outros).

Nesse sentido, se alterássemos (1) para simplesmente "João martelou a lata", nenhum estado resultante seria acarretado, mesmo que saibamos que haveria um estado de a lata estar martelada. Mas isso não significa muita coisa, porque o fato de a lata estar martelada não significa que ela sequer tenha mudado de estado, ao contrário do que ocorre nos casos em (2), em que a porta e a ponte mudam completamente de estado: a porta passa de aberta à fechada e a ponte de não existente a existente. Imagine, por exemplo, que a lata é bastante forte e, mesmo depois de muitas marteladas, ela continua intacta. Por essa razão, predicados como "martelar a lata", "empurrar o carrinho", "esfregar o chão", "chorar", entre muitos outros, são conhecidos na literatura como "atividades", já que podem perdurar por tempo indeterminado e não acarretam, necessariamente, uma mudança de estado.

Assim, fica diferenciada a ideia de estado resultante, presente nos eventos que acarretam lexicalmente mudança de estado (por achievements e accomplishments), e resultatividade, presente nos eventos que não acarretam lexicalmente tal mudança e necessitam do acréscimo de um elemento para indicá-la.

Neste artigo, vamos defender que o acréscimo de um adjetivo em sentenças como (2) acarreta simplesmente uma modificação de estado resultante (3), tal como defende Barbosa (2008), ao contrário de Lobato (2004). O que se argumenta é que tais sentenças já carregam nos sintagmas verbais (verbo+objeto direto, basicamente) o estado final. 
(3) a. João fechou a porta firme.

b. O engenheiro construiu a ponte sólida.

Por outro lado, ao contrário de Barbosa (2008), vamos afirmar que o PB tem, sim, construções resultativas, constituídas não de adjetivos, mas de um sintagma preposicional (PP) com oração infinitiva encabeçado por "até", como em (4).

(4) a. João martelou a lata até achatar.

b. Maria esfregou o chão até brilhar.

Nossa intenção é mostrar que, se do ponto de vista sintático não podemos assumir que haja construções resultativas em PB (ver BARBOSA, 2008), do ponto de vista semântico isso é perfeitamente possível. Tomamos como base a semântica de eventos de Parsons (1990), para quem, numa sentença resultativa como (1), há um evento e que causa um evento e' e esse evento e' acarreta um estado resultante $\mathbf{s}$. Veremos os detalhes dessa análise na primeira seção. Por isso, assumimos a noção de resultatividade como um evento complexo, com dois núcleos verbais (como em "João martelou a lata até amassar") em que há dois eventos verbais e um estado resultante desse evento complexo, sem que tal estado seja acarretado diretamente do sintagma verbal (VP). Como nosso foco não é discutir uma classificação para as resultativas, mas simplesmente atestar sua existência em PB, indicamos os trabalhos de Leite (2006) e Oliveira (2013) para pesquisas sobre possíveis classificações.

Foltran (1999), Lobato (2004) e Barbosa (2008) são alguns dos trabalhos que já analisaram essa questão com relação ao PB. As duas primeiras concordam que sentenças como as apresentadas em (5) possam ser chamadas de "construções resultativas" em PB, fato do qual Barbosa (2008) discorda.

(5) a. Maria cortou o cabelo curto.

b. O engenheiro construiu a ponte sólida.

Para Lobato (2004), as sentenças em (5) podem ser consideradas resultativas porque cumprem os três critérios que a autora estabelece para essa classe: a) há um predicativo do objeto ("curto", "sólida"); b) há a atribuição de uma nova propriedade ("curto", "sólida") ao referente do objeto ("o cabelo", "a ponte") como efeito da ação verbal ("cortar", "construir") e c) o evento é interpretado como processo culminado (accomplishment). Veremos na segunda seção, os detalhes dessa análise, e mostraremos que ela está equivocada, se levarmos em conta as propriedades mais intrínsecas de uma construção resultativa como em (1).

Barbosa (2008) se configura como um dos trabalhos mais representativos em PB sobre o assunto. Ele aborda diversas análises que foram propostas para os casos 
das resultativas e conclui que não há resultativas em PB, nem semântica, nem sintaticamente equivalentes às resultativas do inglês. Para o autor, nos casos em (5), os adjetivos não cumprem o papel de delimitar a atividade, como acontece com o adjetivo em (1), porque, em (5), os estados resultantes estão presentes, mesmo se os adjetivos forem excluídos das sentenças. Por isso, Barbosa (2008) dirá que o que acontece ali é uma "modificação do estado resultante" por parte do adjetivo. Além disso, para o autor, o PB não construiria sentenças como o inglês por uma diferença na estrutura das duas línguas. Ainda na segunda seção, traremos mais detalhes da análise do autor e suas justificativas para negar que as sentenças em (5) sejam resultativas.

Finalmente, na última seção deste trabalho, defenderemos que as sentenças resultativas do inglês podem ser capturadas, sim, por sentenças resultativas no PB, mas com estruturas diferentes. De alguma forma, nossa análise leva em conta a afirmação de Marcelino (2007) e Barbosa (2008) de que o PB e o inglês têm estruturas diferentes e sugere que a maneira pela qual o inglês constrói sua sentença resultativa é com um adjetivo delimitador do evento (como "flat"), enquanto o PB constrói sua resultativa por meio de uma oração infinitiva, antecedida da preposição "até", tal qual ocorre em (4), repetidas a seguir

(4) a. João martelou a lata até achatar.

b. Maria esfregou o chão até brilhar.

Nos casos acima, "até achatar" e "até brilhar" delimitam os eventos de "martelar a lata" e "esfregar o chão". Na terceira seção, mostraremos quais as previsões a serem feitas se considerarmos que os casos em (4) formam sentenças resultativas e veremos que todas elas vão ao encontro do que temos com as resultativas em inglês. Isso nos leva a considerar que o PB tem construções resultativas infinitivas, que denotam o evento e acarretam o estado resultante, enquanto o inglês tem construções resultativas com adjetivos, que denotam o estado resultante e acarretam o evento que levou a esse resultado.

\section{Sobre as sentenças resultativas em inglês}

Nesta seção, apresentamos a proposta de Parsons (1990) sobre a semântica de sentenças denominadas de resultative tags, as quais chamaremos simplesmente de resultativas. De acordo com o autor, as resultativas envolvem uma relação de causa (CAUSE) entre dois eventos (e, e') e uma relação de mudança (BECOME) entre o evento (e') e um estado resultante (s). Diferentemente da primeira, a relação de mudança acontece por acarretamento: quando o evento e' ocorre, ele acarreta necessariamente o estado resultante $\mathbf{s}$. Veremos a relação de acarretamento com 
mais detalhes quando tratarmos dos casos em PB. Por enquanto, observemos os exemplos em (6).

(6) a. John hammered the metal flat.

'João martelou o metal até achatar'

b. Sam pulled the rope taut.

'Sam puxou a corda até esticar'

Parsons (1990) sustenta que uma sentença resultativa como (6a) é relativamente parecida com uma sentença causativa do tipo "John flattened the metal" ("João achatou o metal"). A diferença entre as duas reside no fato de apenas a resultativa (6a) mostrar a maneira pela qual João fez a ação que resultou em o metal ficar chato ${ }^{1}$. Já o adjetivo em uma sentença resultativa tem o papel de delimitar a atividade (no caso, a atividade de martelar o metal ou puxar a corda), indicando o estado resultante em que o tema/objeto ficou.

Sendo assim, a sentença em (6a) pode ser analisada da seguinte maneira: "João martelar o metal" é evento e; o "achatar do metal" é o evento e'; e "o metal ficar achatado" é o estado resultante $\mathbf{s}$. Já a sentença em (6b) pode ser dividida assim: "Sam puxar a corda" é o evento e; o "esticar" da corda é o evento e'; e "a corda ficar esticada" é o estado resultante $\mathbf{s}$. Nos dois casos, o evento e causa o evento $\mathbf{e}^{\prime}$ e este acarreta o estado $\mathbf{s}$. Tal acarretamento é possível porque o tema do evento e' e do estado s são, necessariamente, o mesmo: em (6a), "the metal" ("o metal"), e em (6b), "the rope" ("a corda"). É preciso sublinhar, no entanto, que as sentenças resultativas em inglês não apresentam explicitamente o evento e' por meio de um verbo; nos casos em (6), ele pode ser deduzido pelos adjetivos, os estados s, que compõem a sentença, como mostramos no parágrafo anterior: chato(s)/achatar(e'); esticado(s)/esticar(e').

Agora, podemos apresentar a forma lógica que Parsons (1990) propõe para as resultativas. Na forma lógica dessas sentenças, é preciso que sejam descritos os dois eventos (e, e') e o estado resultante (s); além disso, o tema de e' precisa ser o mesmo de $\mathbf{s}$. Parsons (1990) oferece a forma lógica em (7) para a sentença resultativa apresentada em $(6 a)^{2}$.

(7) $\exists e[$ Agente(e, joão) \& Martelar(e) \& Tema(e,o metal) \& ヨe'[Tema(e',o metal) \& CAUSE $\left(e, e^{\prime}\right)$ \& $\exists$ s[Achatado(s) \& Tema(s,o metal) \& BECOME (e',s)]]]

Perguntar como alguém fez uma ação é um teste para Kratzer (2005) separar as resultativas adjetivas do alemão de outras que ela chama de "contra-exemplos". Indicamos os trabalhos de Knöpfle (2010, 2011) para maiores detalhes sobre a comparação entre o PB e o alemão quanto à resultatividade.

2 Apresentamos uma versão resumida da proposta de Parsons, sem os elementos que se referem ao tempo/ duração: Cul e Hold. 
Em palavras: existe um evento e, tal que o agente de e é "João"e o evento e é "martelar" e o tema de e é "o metal", e existe um evento e', tal que o tema de e' é "o metal" e e desencadeia (causa) e', e existe um estado $\mathbf{s}$, tal que s é "achatado" e o tema de s é "o metal" e e' resulta $\mathbf{s}$.

Segundo Parsons (1990), o evento causativo e' não é explícito, como podemos notar na forma lógica; por outro lado, é possível saber como o agente causou a mudança: em (6a) sabemos que foi martelando que João achatou o metal. Voltaremos a essa questão ao longo do trabalho porque ela será relevante para os casos do PB. Mas o que podemos fazer com alguma segurança é deduzir, dessa forma lógica particular em (7), a forma lógica comum para as resultativas em (8).

(8) $\exists$ e $\exists x \exists y\left[\right.$ Agente(e,x) \& Evento(e) \& Tema(e,y) \& $\exists e^{\prime}[$ Evento(e') \& Tema(e',y) \& CAUSE(e,e') \& $\exists$ s[Estado(s) \& Tema(s,y) \& BECOME (e',s)]]]

Voltando à composição das resultativas e à ausência do evento causativo, poderíamos argumentar que, se não temos o evento causativo explícito, temos o estado; e é exatamente desse estado que poderíamos inferir o evento causativo. No caso, de (6a), poderíamos dizer que o evento e é "martelar", e' é "achatar" e o estado s é "estar chato/achatado". Essa inferência é importante por uma razão: quando tratarmos das resultativas em PB na terceira seção, argumentaremos que o elemento ausente será o estado $\mathbf{s}$, mas ele poderá ser inferido, porque nessa língua o evento causativo e' está explícito. Nesse caso, a diferença do PB para o inglês estaria no fato de, na primeira língua, o estado ser acarretado a partir do evento denotado pela oração infinitiva presente no sintagma com "até" ("João martelou a lata até achatar"), enquanto, na segunda língua, o evento ser acarretado a partir do estado denotado pelo adjetivo presente na sentença ( "John hammered the metal flat').

A fim de traçarmos um paralelo, vamos ver como seria a forma lógica de uma sentença como (6a), mas sem a presença do adjetivo que delimita o evento, ou seja, uma sentença sem resultatividade, e com características de atividade.

(9) a. João martelou a lata.

b. $\quad \exists e[$ Agente(e, joão) \& Martelar(e) \& Tema(e, a lata)]

Conforme anunciamos na introdução, nesse caso não temos qualquer estado resultante que é acarretado lexicalmente do VP. Sabemos que a lata fica num "estado de martelada", mas isso não muda, necessariamente, seu estado original. Ao martelar a lata, o sujeito pode amassá-la, desamassá-la ou mesmo não alterar em nada seu estado, se for uma lata resistente, por exemplo. Exatamente por isso, do ponto de vista linguístico, nenhuma mudança de estado pode ser acarretada por esse evento sem um contexto específico. Por outro lado, no caso de (6a), há 
um estado que é resultado da ação de martelar, mas é indicado, precisamente, pelo adjetivo, o que justifica a forma lógica da sentença em (7).

Na seção seguinte, quando tratarmos dos casos do PB, falaremos das construções com estado resultante, em que o estado presente na forma lógica é lexicalmente acarretado, sendo, também, diferente dos casos com resultativas.

Nesta seção, apresentamos a proposta de Parsons (1990) sobre as resultativas em inglês e observamos que as principais características das resultativas são a) presença de dois eventos (e,e'), em que o primeiro causa (CAUSE) o segundo; b) presença de um estado (s), que é resultado da mudança (BECOME) do evento (e') e não é acarretado pelo aspecto do sintagma verbal; c) o tema de e' é o mesmo de $\mathbf{s}$. Em inglês, o evento e' não está explícito, mas pode ser inferido do estado resultante presente na sentença. Existe uma grande discussão sobre a existência ou não de resultativas em $\mathrm{PB}$ e vamos apresentar dois autores que tratam do assunto: Lobato (2004), para quem o PB tem resultativas, e Barbosa (2008), para quem elas são ausentes na nossa língua.

\section{As construções resultativas em PB}

A fim de responder a questão-título do seu trabalho - Afinal, existe a construção resultativa em português? -, Lobato (2004) inicia com a observação de que construções resultativas do tipo (6a), repetida a seguir, são produtivas em inglês, mas não em PB.

(6) a. John hammered the metal flat.

'João martelou o metal até achatar'

A autora observa que essas construções são formadas por um predicado complexo, composto por quatro elementos: a) objeto direto, que denota um indivíduo e recebe a predicação por meio da ação verbal; b) ação verbal, o único evento na construção; c) predicado secundário, que expressa a propriedade que é resultado da ação; e d) predicado principal, composto pelo verbo e o objeto.

Lobato (2004) acrescenta ainda que a propriedade expressa pelo predicado secundário delimita ou teliciza o evento. Essa observação é importante porque nos autoriza a assumir que o evento denotado pelo predicado - "hammering the metal" (martelar o metal), em (6a) - não seja télico, não tenha um ponto final determinado e, portanto, cabe ao predicativo - "flat" (achatado), no caso - informar em que ponto o evento para. Assim, podemos dizer que (6a) descreve uma situação em que João martelou o metal até que o metal ficasse chato/achatado e esse predicativo é que põe um ponto final na atividade de martelar que João exercia sobre o metal. 
Ora, se o predicativo delimita o evento, a observação de Lobato (2004) nos leva à previsão de que apenas sentenças cuja leitura não seja télica, ou seja, cuja leitura não acarrete um ponto final da atividade, possam construir sentenças resultativas. Mas, surpreendentemente, não é isso o que a autora sugere acontecer no PB.

Para Lobato (2004), em PB, as resultativas são formadas com dois tipos de predicado: processos culminados - conhecidos como accomplishments - e culminações - conhecidos como achievement $s^{3}$. Mas isso é um tanto quanto contraditório, porque, se esses eventos têm um ponto final intrínseco, eles não precisam ser delimitados pelo predicativo. No caso do inglês, como em (6a) acima, "martelar o metal" pode ser considerado um predicado de atividade (predicado atélico, portanto), e o papel do predicativo "chato/achatado" é justamente o de delimitar a atividade, i.e., telicizá-la: "João martelou o metal até ele ficar chato/ achatado".

Lobato (2004) defende ainda que as sentenças em (10) sejam resultativas em PB, por obedecerem a três critérios: a) há um predicativo do objeto; b) há uma atribuição de nova propriedade ao referente do objeto, como efeito da ação verbal; e c) há uma interpretação do evento como processo culminado (accomplishment).

(10) a. O engenheiro construiu a ponte sólida.

b. João fabricou a cadeira torta.

c. Joana cortou o cabelo curto.

d. O rio congelou bem sólido.

Lobato (2004) afirma que os predicativos destacados são uma nova propriedade atribuída ao objeto, como resultado da ação verbal: "sólida" é o resultado da construção da ponte; "torta" é o resultado da fabricação da cadeira, e assim por diante. Além disso, os eventos podem ser lidos como accomplishments e um teste para isso é que essas sentenças aparecem com um sintagma preposicional (PP) delimitador como "em 2 meses", mas não com um PP durativo como "por 2 meses". Tanto as sentenças em PB (11) ou inglês (12) passam no teste de Lobato (2004).

(11) a. O engenheiro construiu a ponte sólida em 2 meses/“por 2 meses.

b. João fabricou a cadeira torta $\mathbf{e m} 2$ dias/“por 2 dias.

c. Joana cortou o cabelo curto em 10 minutos/“por 10 minutos.

d. O rio congelou bem sólido em 2 dias/*por 2 dias.

(12) John hammered the metal flat in $\mathbf{2}$ hours/*for $\mathbf{2}$ hours.

\footnotetext{
Para Vendler (1967), accomplishments ("construir a ponte", e.g.) e achievements ("congelar", e.g.) possuem um ponto final/uma delimitação intrínseca e, por isso, são chamados de télicos. Estados ("ser jovem", e.g.) e atividades ("correr", e.g.) não possuem um ponto final intrínseco e, por isso, são chamados de atélicos. Neste artigo, não temos espaço para discutir essas classes detalhadamente, por isso remetemos o leitor aos trabalhos de Vendler (1967), Rothstein (2004), Wachowicz e Foltran (2006) e Wachowicz (2008), entre outros.
} 
No entanto, vemos que esse teste não garante que a delimitação dos eventos em (11) seja atribuída pelo predicativo. Se assim o fosse, esperaríamos que a sua retirada da sentença gerasse sentenças em que o PP durativo fosse aceito e o PP delimitador não. Mas não é isso o que ocorre, como vemos nos dados em (13).

(13) a. O engenheiro construiu a ponte em 2 meses/“por 2 meses.

b. João fabricou a cadeira em 2 dias/ ${ }^{\star}$ por 2 dias.

c. Joana cortou o cabelo em 10 minutos/*por 10 minutos

d. O rio congelou em 2 dias/ ${ }^{*}$ por 2 dias

Como o leitor percebe, o terceiro critério que Lobato (2004) sugere para as resultativas em PB - que o processo precisa ser culminado - não faz sentido por duas razões: primeiro, porque a autora já havia dito que apenas accomplishments e achievements, ambos télicos, são as únicas classes que formam resultativas em PB, mas, nesse caso, o adjetivo perderia a função de delimitar o evento, já que o evento já seria delimitado; depois, porque nem mesmo o teste proposto por ela é capaz de confirmar o critério estabelecido.

Poderíamos ainda nos valer do teste mostrado por Knöpfle (2010) e proposto por Kratzer (2005) para identificar as verdadeiras sentenças resultativas. Dada uma sentença, podemos utilizar a perguntar "Como...?". Se a pergunta e a resposta formarem um todo não gramatical, a sentença é resultativa, porque o adjetivo estará funcionando como um delimitador da atividade. Por outro lado, se a pergunta e a resposta formarem um todo gramatical, a sentença não é resultativa, porque o adjetivo está funcionando como um advérbio, tratando do modo como a ação foi feita, i.e., é um modificador e não um delimitador. Isso fica bastante claro no trabalho de Knöpfle (2010), mas por questões de espaço deixamos os detalhes de lado. Passemos ao teste.

Olhando para os dados abaixo, vemos que nas sentenças em (14-15) não há gramaticalidade entre a pergunta e a resposta, o que significa que estamos diante de sentenças resultativas verdadeiras. No entanto, nas sentenças em (16-17) há gramaticalidade na relação entre pergunta e resposta, o que nos leva a assumir que tais sentenças não são resultativas.

(14) a. John hammered the metal flat.

b. ${ }^{*}$ How did John hammer the metal? Flat. *Como John martelou o metal? Chato.

(15) a. Sam pulled the rope taut.

b. *How did Sam pull the rope? Taut. *Como Sam puxou a corda? Esticada.

(16) a. João construiu a ponte sólida.

b. Como João construiu a ponte? Sólida. 
(17) a. Maria cortou o cabelo curto.

b. Como Maria cortou o cabelo? Curto.

Esses e outros fatos levaram Barbosa (2008) a argumentar que não temos resultativas em $\mathrm{PB}$ que sejam semântica ou sintaticamente similares àquelas do inglês e que, nos casos apresentados por Lobato (2004), o que ocorre é uma modificação do estado resultante (e não uma delimitação do evento) feita pelo predicativo.

Mas, antes mesmo de compararmos a diferença entre uma construção resultativa e outra de estado resultante, vamos verificar a diferença, na forma lógica, entre as sentenças "O engenheiro construiu a ponte" (18a) e "O engenheiro construiu a ponte sólida" (18b), a partir da semântica de eventos que assumimos aqui.

(18) a. $\exists e\left[\right.$ Agente(e, o engenheiro) \& Construir(e) \& $\exists e^{\prime}[$ Tema(e', a ponte) \& CAUSE (e,e') \& $\exists$ s[Estar-construído(s) \& Tema(s, a ponte) \& BECOME (e',s)]]]

b. $\exists e\left[\right.$ Agente(e, o engenheiro) \& Construir(e) \& $\exists e^{\prime}[$ Tema(e', a ponte) \& CAUSE(e,e') \& $\exists \mathrm{s}[$ Estar-construído(s) \& Tema(s, a ponte) \& BECOME (e',s) \& Estar-sólida(s)]]]

Como se vê, na forma lógica em (18a), há um estado resultante acarretado lexicalmente do VP accomplishment "construir a ponte"; já em (18b), há o mesmo estado resultante, pois é acarretado lexicalmente, acrescido de um outro estado modificador, "estar-sólida". Este estado modifica aquele, atribuindo-lhe uma característica.

Agora, sim, podemos comparar as resultativas com este último caso em (18b). Vamos repetir as formas lógicas por conveniência, sendo que (19a) é equivalente a "João martelou a lata até achatar" ("John hammered the metal flat") e (19b) a "O engenheiro construiu a ponte sólida".

(19) a. $\quad \exists e[$ Agente(e, joão) \& Martelar(e) \& Tema(e, a lata) \& ヨe'[Tema(e', a lata) \& CAUSE (e,e') \& $\exists$ s[Achatado(s) \& Tema(s, a lata) \& BECOME (e',s)]]]

b. $\exists e\left[\right.$ Agente(e, o engenheiro) \& Construir(e) \& $\exists e^{\prime}[$ Tema(e', a ponte) \& CAUSE(e,e') \& $\exists$ s[Estar-construído(s) \& Tema(s, a ponte) \& BECOME (e',s) \& Estar-sólida(s)]]]

Em primeiro lugar, na forma lógica das resultativas, em (19a), percebemos que o tema se encontra já na primeira parte, enquanto o mesmo não acontece com a forma lógica com modificação secundária, em (19b). Isso ocorre porque as resultativas são geradas de atividades, em que o tema não delimita o evento para que haja um estado resultante. Já o segundo caso é gerado de accomplishments, 
em que o tema participa da delimitação do evento e é resultado de ações anteriores (por isso argumento de CAUSE). Em segundo lugar, o estado resultante de (19b) é "estar-construído", que deriva do verbo "construir", graças às características dos verbos de accomplishment (ver DOWTY, 1979; PARSONS, 1990; ROTHSTEIN, 2004, entre outros). O segundo estado é apenas modificador desse primeiro. Já no caso das resultativas, o estado resultante (ou a resultatividade) é "estar-chato", que deriva do adjetivo "chato" ( "flat"). Como "martelar" não acarreta, necessariamente, um estado resultante que modifica o estado do tema, tal estado deve vir de outro elemento na sintaxe. Finalmente, por ter características de atividade, ou seja, não ter uma delimitação natural (ser atélico), "martelar a lata" recebe a delimitação quando o evento alçancar o resultado final do tema, no caso quando estiver chato/ achatado. Essas são as principais características entre as sentenças resultativas e as de modificação secundária do ponto de vista de suas formas lógicas.

Para voltar ao debate com os trabalhos mais recentes, vamos discordar de Barbosa (2008) quanto à afirmação de que não há resultativas em PB equivalentes às do inglês, nem semântica, nem sintaticamente. O autor defende que os adjetivos presentes nas sentenças em (10) modificam o estado resultante e não delimitam o evento descrito, o que o leva a assumir a inexistência de construções resultativas em PB, tal como há em inglês, posição contrária à de Lobato, que classifica os casos em (10) como resultativas. Para Barbosa (2008), a resposta para a ausência de resultativas em PB, ao contrário do inglês, vem da estrutura diferente dessas duas línguas. Indicamos ao leitor interessado o trabalho de Barbosa (2008), já que não podemos resumi-lo aqui, por questões de espaço e complexidade.

Além daquilo que já descrevemos, outro ponto em que podemos demonstrar o equívoco da análise de Lobato (2004) sobre resultativas em PB vem das classes vendlerianas que formam as sentenças resultativas. Para a autora, em PB essas construções são formadas com accomplishments e achievements, mas isso iria contra um fato atestado pela literatura de que as resultativas transformam atividades em accomplishments - e aqui cito alguns autores apresentados já em Barbosa (2008): Levin e Rappaport-Hovav (1995); Dowty (1979); Hoekstra (1988, 1992), entre outros.

Barbosa (2008, p.31) mostra que, para Levin e Rappaport-Hovav (1995), por exemplo, as resultativas são compostas por um sintagma resultativo (adjetival ou preposicional) "[...] e só se diferenciam de accomplishments simples por expressarem o estado resultante no predicado secundário, enquanto outros accomplishments o expressam no verbo." Assim, parece claro que as sentenças "resultativas" do PB defendidas por Lobato (2004) não sejam as mesmas do inglês, exatamente como defende Barbosa (2008).

Até aqui, pudemos ver algumas diferenças entre a proposta de Lobato (2004) e Barbosa (2008): a primeira afirma que i) há resultativas em PB; ii) elas 
são construídas por accomplishments ou achievements; iii) o adjetivo é resultado da ação verbal. Já Barbosa (2008) defende que i) não há resultativas em PB; ii) as resultativas reais (as do inglês) são construídas com atividades mais um estado delimitador; iii) o adjetivo nas chamadas "resultativas em PB" modifica o estado resultante, mas não o evento em si. Na próxima seção, vamos defender que existem resultativas em $\mathrm{PB}$, semanticamente similares às do inglês, embora sua estrutura não seja a mesma.

\section{Sobre as resultativas infinitivas}

Vamos assumir, com Barbosa (2008), que as sentenças chamadas por Lobato (2004) de resultativas, na verdade, não o são, porque o adjetivo ali presente modifica o estado resultante e não delimita o evento anterior. No entanto, vamos discordar de Barbosa (2008) quando ele afirma não existirem resultativas em PB nem semântica, nem sintaticamente equivalentes às do inglês. A tese que defendemos nesta seção é de que há, sim, resultativas em PB. Mas, ao contrário do inglês - talvez justamente pelas questões de estrutura apontadas em Barbosa (2008) -, elas não são formadas por um sintagma adjetival (AP), mas por uma oração no infinitivo, dentro de um PP adjunto nucleado pela preposição "até", como vemos em (20) a seguir.

(20) a. João martelou o metal até achatar.

b. Maria esfregou o chão até brilhar.

c. Maria esticou a massa até afinar.

Propomos chamar essas sentenças de resultativas infinitivas, a fim de preservar uma nomenclatura que se ligue semanticamente com as resultativas do inglês, mas também mostrar que há uma diferença na sua estrutura. Verificaremos se, de fato, os PPs destacados delimitam o evento.

Em todos os casos, qualquer ação do sujeito, por menor que seja, acarreta uma ação sobre o tema. Por exemplo, qualquer martelada que o João der na lata, podemos dizer que a lata foi martelada; qualquer esfregada que a Maria der no chão, ele foi esfregado; e qualquer mínima esticada que ela der, a massa foi esticada. Tais fatos são típicos de atividades, em que ações mínimas correspondem ao que se descreve pelo predicado, ao contrário de accomplishments como "construir a ponte", ou "comer a maçã" - para detalhes sobre esse ponto, ver Rothstein (2004) e Wachowicz (2008), entre outros. Apesar disso, não podemos dizer que tais eventos tenham um "final natural", porque se pode fazer qualquer um dos eventos em questão por tempo indeterminado, ao contrário do que ocorre com eventos que têm delimitação natural, como "construir a ponte", "comer a maçã", "chegar", "morrer" etc. 
Partindo da hipótese de que as sentenças em (20) sejam resultativas, e depois das discussões sobre o tema apresentadas neste trabalho, fazemos as seguintes previsões:

(21) Previsões para as resultativas infinitivas em PB

I. O PP adjunto na resultativa do PB terá o mesmo papel do adjetivo em inglês nas resultativas daquela língua, ou seja, delimita/teliciza o evento anterior, interpretado como atividade.

II. O evento que ocorre dentro do PP na resultativa em PB deverá, obrigatoriamente, denotar uma mudança de estado, a fim de delimitar a atividade e acarretar o estado resultante do tema.

III. As resultativas em inglês denotam o estado $\mathbf{s}$ e acarretam o evento $\mathbf{e}^{\prime}$ porque são expressas por um adjetivo; em PB, as resultativas infinitivas denotam o evento e' e acarretam o estado s porque são expressas por uma oração.

IV. Para preservar a noção de resultatividade, o tema de e' e de $\mathbf{s}$ deverá ser o mesmo.

V. Sendo o mesmo, o tema não precisa, necessariamente, ser realizado foneticamente no PP adjunto; além disso, ele pode ser retomado por um pronome correferente, ao contrário do inglês, em que nenhum tema aparece realizado abertamente no AP adjunto da resultativa.

Temos visto ao longo deste trabalho que os APs das sentenças resultativas em inglês - "flat"e "clean" em (22a-b), por exemplo - são capazes de delimitar o evento, informando assim o resultado/estado do objeto/tema com o fim do evento. Em PB, os PPs adjuntos das resultativas infinitivas têm uma função similar: eles delimitam o evento, informando o resultado do tema com o fim do evento (23a-b).

(22) a. John hammered the metal flat.

'John martelou o metal até achatar/ficar achatado'

b. They wiped the table clean.

'Eles passaram um pano na mesa até limpar/ficar limpa'

(23) a. João martelou a lata até achatar.

b. Maria esfregou o chão até brilhar.

Tal qual os APs destacados em (22), os PPs destacados em (23) têm função delimitadora, cumprindo a primeira previsão de (21I): em (23a), "até achatar" informa que João parou a atividade de martelar a lata no momento em que o objeto atinge o estado de estar achatado; temos, portanto, um estado resultante dado implicitamente; em (23b), "até brilhar" informa que Maria parou a atividade de 
esfregar o chão no momento em que o objeto atinge o estado de estar-brilhante; temos, portanto, um estado resultante implícito.

Nesse ponto, fica evidenciada a relação de acarretamento entre o evento e' e o estado resultante $\mathbf{s}$ sobre a qual havíamos comentado na primeira seção. Como se vê pelas sentenças acima, se for verdade que João martelou a lata até achatar, é necessariamente verdade que a lata ficou chata/achatada e isso caracteriza uma relação de acarretamento; da mesma forma, se for verdade que Maria esfregou o chão até brilhar, é necessariamente verdade que o chão ficou brilhante. É por isso que assumimos aqui que o estado resultante das resultativas infinitivas do PB é dado implicitamente, diferentemente do inglês, em que o estado resultante está explícito e o evento que leva o objeto a tal estado é acarretado pelo tema.

A segunda previsão (21II) também é plenamente cumprida, porque, em (23), o evento que ocorre dentro do PP denota uma mudança de estado ("achatar" e "brilhar"), garantindo a delimitação da atividade e o estado resultante do tema. No entanto, a segunda previsão também evita que as resultativas tenham um evento de atividade no PP adjunto, porque, nesse caso, não haveria delimitação, e, por consequência, nenhum estado resultante como acarretamento. Isso pode ser atestado pelas sentenças em (24).

(24) a. *João martelou a lata até pintar/correr/cantar.

b. *Maria esfregou o chão até pintar/correr/cantar.

Como vemos em (24), os PPs nucleados por "até" são compostos de atividades; por isso, as sentenças não são aceitáveis em PB. Já que tais PPs não são capazes de delimitar os eventos de "martelar a lata" e "esfregar o chão", não temos estado resultante nem sentenças resultativas.

O leitor poderia nos questionar sobre a previsão em (21II), alegando que predicados como "brilhar" ou "reluzir" seriam atividades e apareceriam naturalmente na posição de delimitadores nas construções resultativas. Assim, "Maria esfregou o chão até brilhar" (20b) ou mesmo "João martelou a lata até reluzir" seriam sentenças perfeitamente aceitáveis e que argumentariam contra a previsão em questão. Na verdade, o que se pode perceber dessas sentenças é que o que está em jogo não é a atividade em si de brilhar ou reluzir, mas o seu começo. Assim, a intuição mais natural seria a de que tais sentenças deveriam ser lidas como "Maria esfregou o chão até começar a brilhar" e "João amassou a lata até começar a reluzir", o que confirma nossa previsão de que o evento denotado pelo predicado nesse PP precisa indicar mudança de estado. Os trabalhos sobre verbos aspectuais mostram que "começar" + VP é uma perífrase com características de achievement, ou seja, de mudança de estado (ver LACA, 2002, 2004; WACHOWICZ, 2007, entre outros). 
Com relação à terceira previsão (21III), precisamos lembrar que, para Parsons (1990), as resultativas são compostas de dois eventos (e,e'), que mantêm uma relação de CAUSE entre si, e de um estado $\mathbf{s}$, que é resultado do BECOME de e'. Vejamos quais são os eventos e o estado de (22a), bem como a relação entre eles:

(25) a. evento e: martelar o metal; estado s: o metal estar chato/achatado ( $\rightarrow$ evento e': achatar o metal)

b. martelar o metal(e) CAUSE achatar o metal(e'); achatar o metal(e') BECOME o metal estar chato/achatado(s)

A sequência em (25a) mostra que o evento e e o estado $\mathbf{s}$ são dados explicitamente em (22a) e é assim com todas as sentenças resultativas em inglês; já o evento e' não é dado explicitamente, ou seja, não há uma oração para evidenciá-lo, mas ele é facilmente inferido a partir do estado $\mathbf{s}$, por isso o colocamos entre parênteses. Por outro lado, a sequência em $(25 b$,$) apresenta$ a relação esperada entre os eventos e o estado da sentença em (22a): o evento e é "martelar o metal" e é causador de um outro evento e', que é "achatar o metal"; finalmente, desse evento e' o objeto/tema se transforma em um estado s, no caso, "chato/achatado".

Em PB, como as resultativas são construídas com um PP composto por uma oração, tanto e quanto e' são expressos explicitamente e o estado $\mathbf{s}$ é acarretado pelo e'. Vejamos as sequências em (26), a seguir.

(26) a. evento e: martelar a lata; evento e': achatar a lata ( $\rightarrow$ estado $\mathbf{s}$ : a lata estar chata)

b. martelar a lata(e) CAUSE achatar a lata(e'); achatar a lata(e') BECOME a lata estar chata(s)

Em (26a), vemos que o estado s pode ser acarretado do evento e', o inverso do que temos em inglês e, em (26b), vemos que o evento e é "martelar a lata" e é causador de um outro evento e', que é "achatar a lata"; finalmente, desse evento e' o objeto/tema se transforma em um estado s, no caso, "chata/achatada". Como o leitor percebe, o que temos em (26b) é exatamente a mesma relação que tínhamos em (25b), o que corrobora nossa tese de que há resultativas em PB, tal qual em inglês, ao menos do ponto de vista semântico.

Quanto à quarta previsão (21IV), chamamos a atenção do leitor para a similaridade entre (25b) e (26b) com relação ao tema. Vamos assumir com Parsons (1990) que o sujeito das eventualidades estativas é um tema (não um agente!). Assim, em (25b) e (26b), o tema de e' é o mesmo tema de s, i.e., "the metal" e "a lata', respectivamente. Alguém poderia dizer que o tema de e é o mesmo de e' e de $\mathbf{s}$, mas não é bem assim, e vamos mostrar o porquê. 
Se estamos assumindo que o papel dos adjuntos numa sentença resultativa é justamente o de delimitar a atividade, nossa previsão é a de que sentenças com verbos de atividade, mesmo sem objetos, possam ser delimitados por esses adjuntos. Isso é comprovado pelos dados a seguir, em inglês (27a-b) e em PB (28a-b).

(27) a. She laughed him out of his patience.

'Ela riu até tirar ele do sério'

b. The sopranos sang us sleepy.

'As sopranos cantaram (tanto) até nos deixarem com sono'

(28) a. Maria riu até tirar o João do sério.

b. João falou até irritar a Maria.

Tanto em (27), quanto em (28), todas as atividades delimitadas - "laugh" (rir), "sing" (cantar), "rir" e "falar" - não têm objeto direto, mas apenas sujeito4. Sendo assim, não podemos dizer que o tema de e, e' e s são sempre o mesmo nas sentenças resultativas, mas apenas os temas de e' e $\mathbf{s}$. Vejamos a demonstração disso em (29), por meio do exemplo dado em (28b).

(29) a. evento e: falar; evento e': irritar a Maria ( $\rightarrow$ estado $\mathbf{s}$ : a Maria estar irritada)

b. falar(e) CAUSE irritar a Maria(e'); irrita a Maria(e') BECOME a Maria estar irritada(s)

c. $\quad \exists e\left[\right.$ Agente(e,joão) \& Falar(e) \& $\exists e^{\prime}\left[\operatorname{Irritar}\left(e^{\prime}\right) \&\right.$ Tema(e',maria) \& $\operatorname{CAUSE}\left(e, e^{\prime}\right)$ $\& \exists \mathrm{s}\left[\right.$ Estar-irritada(s) \& Tema(s,maria) \& $\left.\left.\left.\mathrm{BECOME}\left(\mathrm{e}^{\prime}, \mathrm{s}\right)\right]\right]\right]$

Portanto, fica claro que a preservação do tema de e' como o mesmo tema de $\mathbf{s}$ é um fator essencial para se preservar a noção se resultatividade. Isso é importante para a nossa proposta: ela prevê que, mesmo eventos com dois verbos intransitivos, como (30), podem formar uma sentença resultativa.

(30) a. João bebeu até cair.

b. $\quad \exists e[$ Agente(e,joão) \& Beber(e) \& ヨe'[Cair (e') \& Tema(e', joão) \& CAUSE(e,e') \& $\exists$ S[Estar-caído(s) \& Tema(s, joão) \& BECOME(e',s)]]]

Nesse caso, o PP "até cair" possui um evento com mudança de estado e delimita o evento de beber. O evento e' é "cair" e o estado s é "estar-caído" e ambos possuem o mesmo tema: "João". A vantagem da nossa análise é que não precisamos dizer, como Lobato (2004), que as resultativas seriam construções com

\footnotetext{
4 Alguém poderia dizer que os pronomes him (27a) e us (27b) são objetos diretos nessas sentenças. Mas há autores que (a nosso ver, corretamente) argumentam que eles fazem parte do AP adjunto e só estão naquela posição para receber Caso acusativo (KRATZER, 2005; KNÖPFLE, 2010).
} 
verbos transitivos ou apenas com accomplishments e achievements. Dizemos, simplesmente, que o primeiro evento é delimitado por um evento de mudança de estado no PP adjunto.

A nossa quinta previsão (21V) tem relação direta com a anterior. Ela informa que o tema do PP adjunto não precisa, necessariamente, ser realizado foneticamente - como temos em (31a) -, mas nada o impede de o ser. Nesse último caso, o tema é geralmente realizado/retomado com um pronome correferente (31b).

(31) a. João martelou [a lata] $]_{\mathrm{i}}$ até achatar _..

b. João martelou [a lata $]_{i}$ até achatar [ela $]_{i}$.

Em (31a), vemos que o tema "a lata" não aparece foneticamente realizado no PP adjunto, exatamente como temos em inglês, em que o tema do AP adjunto também não é realizado, talvez por questões relativas à checagem de Caso (o que indicamos na nota 4). No entanto, diferentemente do que ocorre no inglês, o tema pode aparecer, como vemos em (31b), em que o pronome "ela" retoma anaforicamente o tema "a lata".

Uma última observação, que favorece nossa análise sobre as resultativas infinitivas, vem do fato de Barbosa (2008, nota 3) apontar a existência de uma leitura de intensidade nas resultativas do inglês. Tal leitura parece ser garantida nas resultativas infinitivas justamente pela presença da preposição "até".

(32) a. João bebeu até cair.

b. Maria cantou até cansar.

Nos dois casos, há claramente uma leitura de intensidade na realização dos eventos de beber e cantar por parte de João e Maria. Essa leitura é evidenciada pela presença dos adjuntos nucleados por "até", que parece exigir um contexto em que os eventos de beber e cantar tenham durado um certo tempo. Por essa razão, a sentença em (32a) não parece ser adequada se João bebeu apenas um grande gole de tequila e caiu. Nesse caso, diríamos que "João bebeu e caiu", e não "até cair".

E para continuarmos na linha de raciocínio de que as construções aqui apresentadas se diferenciam substancialmente das de Lobato (2004), mostramos que a leitura de intensidade não está presente nos casos analisados por esta autora. Vejamos os exemplos em (33).

(33) a. O engenheiro construiu a ponte sólida.

b. Maria cortou o cabelo curto. 
Em ambos os casos, a solidez e o comprimento não estão ligados à intensidade (nem duração) do evento. Além do mais, Maria pode ter cortado seu cabelo curto de uma vez só, com uma única tesourada.

Antes de finalizar a seção, é preciso retomar mais três pontos importantes que podem estar sendo questionados pelo leitor nesse momento. O primeiro é quanto ao fato de em casos como "O coral cantou o hino nacional até a gente dormir" termos um accomplishment ("cantar o hino nacional") numa estrutura a que estou chamando de resultativa. A resposta aqui me parece bastante simples: é sabido na literatura (ROTHSTEIN, 2004; WACHOWICZ, 2008, entre outros) que accomplishments podem ser lidos como atividades, especialmente nos casos em que as partes do processo sejam relativamente similares 5 . No caso apresentado, podemos interpretar a sentença como resultativa, sem dúvida alguma, porque, ou o coral cantou o hino nacional várias vezes até fazer a gente dormir, ou cantou até um ponto específico em que a gente dormiu (provavelmente antes do fim). Nos dois casos, a leitura de accomplishment se perde e dá espaço a uma leitura de atividade, abrindo a possibilidade da construção resultativa.

O segundo ponto é com relação à sentença "Maria cortou o cabelo até ficar curto", que seria equivalente a "Maria cortou o cabelo curto". Sendo equivalentes, o leitor questionaria como explicaríamos o fato de apenas a primeira ser resultativa, enquanto a segunda, como mostrado no artigo, expressa modificação de estado resultante. Para mim e para outros falantes do PB para os quais perguntei, as duas sentenças não são equivalentes. Embora se possa acarretar a segunda a partir da primeira, em "Maria cortou o cabelo até ficar curto" a interpretação apontada pelos falantes é de que Maria foi ao cabeleireiro e lá acontecia o seguinte fato: ele cortava um pouco, e ela pedia para cortar mais; ele cortava um pouco, e ela dizia a mesma coisa, e assim até o cabelo ficar curto. Essa intuição vai ao encontro daquilo que defendo no artigo: as resultativas infinitivas servem para delimitar uma atividade e, em muitos casos, têm uma leitura de intensidade inferida.

O último ponto é uma previsão: seguindo a proposta defendida neste artigo, o leitor poderia esperar resultativas infinitivas também no inglês, como em "John hammered the metal until flat". A resposta negativa se justifica por duas razões: primeiro, não precisamos assumir que as línguas tenham exatamente as mesmas estruturas para expressar os mesmos significados; segundo, se fosse assim, deveríamos esperar, a partir do inglês, que em PB fosse possível "João martelou a lata chata/achatada". Com leitura resultativa, essa sentença não é possível.

Nesses casos, se diz que as sentenças accomplishments são compatíveis com modificadores típicos das atividades, como por "2 horas". É o caso de "O coral cantou o hino nacional por 2 horas", ou "Maria leu o livro por duas horas". Por outro lado, eventos compostos de atividades distintas são mais problemáticos: \#Maria preparou o jantar por 2 horas, ou \#O engenheiro construiu a ponte por 2 meses. 
Nesta seção, vimos que é pertinente se defender a existência de sentenças resultativas em $\mathrm{PB}$, ao menos semanticamente semelhantes ao que temos em inglês. Diferentemente do que se vê em Lobato (2004), em que a resultatividade seria dada pelo adjetivo, como em inglês, aqui propomos que as verdadeiras resultativas em PB sejam construídas com um PP adjunto nucleado por "até". É a delimitação dada por tal PP que produz o efeito resultativo; tal efeito está ausente nas construções apresentadas por Lobato (2004).

\section{Conclusões}

Este trabalho discutiu as sentenças resultativas em inglês e em PB. Vimos que, segundo Parsons (1990), as principais características das resultativas são a) presença de dois eventos (e,e'), em que o primeiro causa (CAUSE) o segundo evento; b) presença de um estado (s), que é resultado da mudança (BECOME) do evento (e') e é dado por um AP, em inglês, e um PP, em PB; c) o tema de é é o mesmo de s. Em inglês, o evento e' não está explícito, mas pode ser inferido justamente do estado presente na sentença. Nossa proposta assume que em PB as resultativas sejam formadas com um PP adjunto nucleado por "até", que tem o papel de delimitador, já que a eventualidade é lida sempre como uma atividade (ver BARBOSA, 2008), exatamente como ocorre em inglês com o adjetivo. Isso é uma vantagem com relação à análise de Lobato (2004) porque, para a autora, as únicas classes aceitas na construção de uma sentença resultativa em PB seriam os accomplishments e alguns achievements, o que seria contraditório, já que essas classes são télicas por natureza, e não precisariam da delimitação do adjetivo. Assumimos, portanto, com Barbosa (2008) que nas construções resultativas do PB, apresentadas em Lobato (2004), o adjetivo não informe um estado resultante, como ocorre em inglês, mas seja um modificador do estado resultante. Mas, ao contrário dele, mostramos que há, sim, construções resultativas em PB que têm os mesmos efeitos semânticos que aquelas apresentadas em inglês.

Uma série de questões foram deixadas de lado aqui, especialmente por razões de espaço. Entre elas está a semântica de "até" nas construções resultativas aqui propostas, para a qual sugiro Grolla (2004). Apesar das lacunas, acreditamos ter contribuído para reacender o debate sobre esse tema intrigante que é a resultatividade nas línguas naturais.

\section{Agradecimentos}

Agradeço à Profa. Dra . Ana Müller e aos participantes do Workshop em Semântica de Eventos, realizado na Universidade de São Paulo (2010), bem como à Andrea Knöpfle, cujos comentários me auxiliaram na reflexão sobre o tema. Sou 
muito grato também aos dois pareceristas anônimos da revista Alfa, cujas críticas e sugestões contribuíram para a melhoria de uma versão preliminar deste artigo. Os erros que ainda persistem são de minha inteira responsabilidade.

BERTUCCI, R. Infinitival resultative constructions in Brazilian Portuguese. Alfa, São Paulo, v.58, n.3, p.623-644, 2014.

- ABSTRACT: This work resumes some discussions on resultative constructions in Brazilian Portuguese, which we found in works by Lobato (2004) and Barbosa (2008). We argue that, although from a syntactic perspective such constructions are not equivalent in English and Brazilian Portuguese (see MARCELINO 2007; BARBOSA 2008), from a semantic point of view we can find some similarities between them. Our proposal comes from Parsons' (1990) analysis on this phenomenon, and we assume that sentences such as João martelou a lata até achatar share both the semantic properties and the logical form of an equivalent English sentence such as John hammered the metal flat, discussed by Parsons (1990). Thus, we propose that we do find resultative constructions in Brazilian Portuguese, in contrast to argued by Barbosa (2008). However, these constructions differ from those analized by Lobato (2004), such as Maria cortou o cabelo curto, which is related to a modification of state, rather than a resultant state, as Barbosa (2008) correctly shows.

- KEYWORDS: State. Modification. Preposition até. Resultative constructions. Event Semantics

\section{REFERÊNCIAS}

BARBOSA, J. W. C. A estrutura sintática das chamadas "construções resultativas em PB". 2008. 134f. Dissertação (Mestrado em Linguística) Departamento de Linguística, Universidade de São Paulo, São Paulo, 2008.

DOWTY, D. Word meaning and montague grammar. Dordrecht: Reidel, 1979.

FOLTRAN, M. J. G. D. As construções de predicação secundária no português do Brasil: aspectos sintáticos e semânticos. 1999. 206f. Tese (Doutorado em Linguística) - Faculdade de Filosofia, Letras e Ciências Humanas, Universidade de São Paulo, São Paulo, 1999.

GROLLA, E. Prepositions, scales and telicity: a case study. In: WEST COAST CONFERENCE ON FORMAL LINGUISTICS, 23., 2004, Somerville. Proceedings... Somerville: Cascadilha Press, 2004. p.293-303.

HOEKSTRA, T. Aspect and theta-theory. In: ROCA, I. M. (Ed.). Thematic structure: Its role in grammar. Dordrecht: Foris, 1992. p.145-173.

Small clause results. Lingua, [S.1.], v.74, p.101-139, 1988.

KNÖPFLE, A. Resultativas adjetivais e o estatuto nu do adjetivo. Estudos da Linguagem, Belo Horizonte, v.19, n.1, p.115-142, jan./jun. 2011. 
A estrutura sintática das resultativas adjetivais no alemão: uma proposta a partir de Kratzer (2005). 2010. 110f. Dissertação (Mestrado em Estudos Linguísticos) - Setor de Ciências Humanas, Letras e Artes, Universidade Federal do Paraná, Curitiba, 2010.

KRATZER, A. Building resultatives. In: MAIENBAUM, C.; WÖLLSTEIN-LEISEN,A. (Org.). Event arguments in syntax, semantics, and discourse. Tübingen: Niemeyer, 2005. p.177-212.

LACA, B. Romance 'aspectual' periphrases: eventuality modification versus 'syntactic' aspect. In: LECARME, J.; GUÉRON, J. (Ed.). The syntax of time. Cambridge: The MIT Press, 2004. p.425-440.

Spanish 'aspectual' periphrases: ordering constraints and the distinction between situation and viewpoint aspect. In: GUTIÉRREZ-REXACH, J. (Ed.). From words to discourse: trends in Spanish semantics and pragmatics. Oxford: Elsevier, 2002. p.61-93.

LEITE, M. A. Resultatividade: um estudo das construções resultativas em português. 2006. 153f. Tese (Doutorado em Língua Portuguesa) - Faculdade de Letras, Universidade Federal do Rio de Janeiro, Rio de Janeiro, 2006.

LEVIN, B.; RAPPAPORT HOVAV, M. Unaccusativity: at the syntax-lexical semantics interface. Cambridge: The MIT Press, 1995. (Linguistic Inquiry Monograph, n.26).

LOBATO, L. Afinal, existe a construção resultativa em português? In: NEGRI, L.; FOLTRAN, M. J.; PIRES DE OLIVEIRA, R. (Org.). Sentido e significação. São Paulo: Contexto, 2004. p.142-179.

MARCELINO, M. O parâmetro de composição e a aquisição/aprendizagem de L2. 2007. 225f. Tese (Doutorado em Linguística) - Instituto de Estudos da Linguagem, Universidade Estadual de Campinas, Campinas, 2007.

OLIVEIRA, C. S. F. de. A construção resultativa e sua representação por bilíngues do par linguístico português do Brasil e inglês. 2013. 119f. Dissertação (Mestrado em Linguística) - Faculdade de Letras, Universidade Federal de Minas Gerais, Belo Horizonte, 2013.

PARSONS, T. Events in the semantics of English: a study in subatomic semantics. Cambridge: The MIT Press, 1990.

ROTHSTEIN, S. Structuring events. Oxford: Blackwell, 2004.

VENDLER, Z. Linguistics in philosophy. Ithaca: Cornell University Press, 1967.

WACHOWICZ, T. Telicidade e classes aspectuais. Revista do GEL, São José do Rio Preto, v.5, n.1, p.57-68, 2008. 
Auxiliary and aspectualizer verbs: some syntactic and semantic distinctions. Revista Letras, Curitiba, n.73, p.223-234, set./dez. 2007.

WACHOWICZ, T. C.; FOLTRAN, M. J. Sobre a noção de aspecto. Caderno de Estudos Linguísticos, Campinas, v.48, n.2, p.211-232, 2006.

Recebido em julho de 2013.

Aprovado em outubro de 2013. 